\title{
Controlled low flow off line sampling of exhaled nitric oxide in children
}

\author{
Q Jöbsis, H C Raatgeep, W C J Hop, J C de Jongste
}

\begin{abstract}
Background-The aim of this study was to validate exhaled nitric oxide (eNO) values obtained with an alternative off line, single breath, low flow balloon sampling method against on line sampling according to ERS and ATS guidelines in children who could perform both methods.

Methods-One hundred and twenty seven white children of median age 14.1 years, all pupils of a secondary school, participated in the study. They performed the two different sampling techniques at three different flows of 50,100, $150 \mathrm{ml} / \mathrm{s}$. Additional measurements were done in random subgroups to determine the influence of the dead space air on eNO values obtained off line by excluding the first $220 \mathrm{ml}$ of exhaled air. All children completed a questionnaire on respiratory and allergic disorders and underwent spirometric tests.
\end{abstract}

Results-The off line eNO values were significantly higher than the on line values at all flows. At $50 \mathrm{ml} / \mathrm{s}$ the geometric mean (SE) off line eNO was 18.7 (1.1) ppb and the on line eNO was 15.1 (1.1) ppb $(p<0.0001)$. However, when dead space air was discarded, off line and on line values were similar: at $50 \mathrm{ml} / \mathrm{s}$ off line eNO was 17.7 (1.0) ppb and on line eNO 16.0 (1.2) ppb. There was a good agreement between off line eNO values without dead space air and on line eNO: for $50 \mathrm{ml} / \mathrm{s}$ the mean on/off line ratio was $0.95(95 \%$ agreement limits 0.63 to 1.27$)$. The off line eNO level at $50 \mathrm{ml} / \mathrm{s}$ in 80 children with negative questionnaires for asthma, rhinitis, and eczema was $13.6(1.0)$ ppb compared with 33.3 (1.1) ppb in the remaining children with positive questionnaires on asthma and allergy and/or recent symptoms of cold $(\mathrm{p}<0.0001)$.

Conclusions-In children, off line assessment of eNO using constant low flow sampling and excluding dead space air is feasible and produces similar results as on line assessment with the same exhalation flow rate. Both sampling methods are sufficiently sensitive to differentiate between groups of otherwise healthy school children with and without self-reported asthma, allergy, and/or colds. We propose that, for off line sampling, similar low flow rates should be used as are recommended for on line measurements.

(Thorax 2001;56:285-289)

Keywords: exhaled nitric oxide; children; measurement; on line sampling; off line sampling
Nitric oxide (NO) is produced by a number of cells in the respiratory tract and has been implicated in the pathophysiology of airway diseases. ${ }^{12}$ NO can be detected in human exhaled air. ${ }^{3}$ Exhaled NO (eNO) has been proposed as a non-invasive marker of airway inflammation, especially in asthma. ${ }^{4}$ Recently, attempts have been made to standardise eNO measurement procedures, recommending on line single breath collection of eNO in adults and children from the age of 6 years. ${ }^{56}$ An alternative method is off line sampling, which has the advantage that it is independent from the analyser. Subjects perform a single deep expiration against a resistance into an NO inert and impermeable balloon. ${ }^{7}$ The content of the balloon is analysed for eNO later. Subjects may be studied outside the laboratory so this method is potentially useful for large epidemiological studies or for home monitoring of asthmatic airway inflammation.

Measurement conditions-including expiratory flow conditions, ambient NO, breath holding, previous forced expiratory manoeuvres, and contamination by nasal $\mathrm{NO}$ - have important effects on eNO concentrations. ${ }^{568}$ NO in exhaled air is flow dependent, an effect that is most pronounced at low flows. ${ }^{9-11}$ To date, most off line measurement techniques for children have not taken into account the dependency on rate of flow. We have previously shown in children that, despite lack of flow standardisation, off line sampling in balloons produces eNO concentrations that are reproducible and similar to those measured on line with high flow rates. ${ }^{7}$ However, we found that eNO discriminates better between different disease states when measured on line with low rates of flow. ${ }^{11}$ The aim of this study was therefore to compare a modified off line single breath, low flow method with on line single breath measurements in children, and to establish a reference range of low flow, off line eNO values in healthy school children.

\section{Methods}

We recruited 127 non-smoking white children of median age 14.1 years (range 12.0-16.1) from a secondary school. They were interviewed with questionnaires on asthma, eczema, and rhinitis, translated and validated from the core questionnaires of the International Study of Asthma and Allergy in Childhood (ISAAC), ${ }^{12}$ and were asked for recent symptoms of cold. Of these 127 children, 80 had negative questionnaires and did not report symptoms of cold during the 3 weeks before the study. These 80 children were regarded as healthy. The remaining 47 children had 


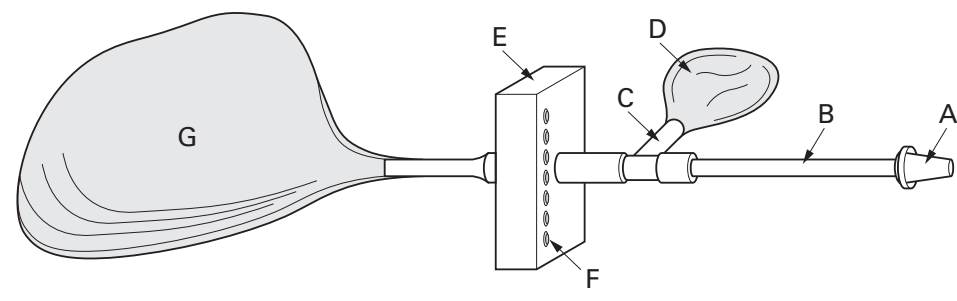

Figure 1 Sampling unit used in the off line collection of exhaled nitric oxide. The mouthpiece $(A)$ is connected to a rigid perspex tube $(B)$ which has a side port $(C)$ with low resistance by which a non-compliant balloon (D) first fills with dead space air. Next, air passes through a small box (E) containing the flow transducer with LED display (F) and an in line flow resistance through which a second balloon $(G)$ fills while oral pressure is raised.

positive questionnaires and/or recent colds and will be referred to as "diseased". The study was approved by the hospital ethics committee and written informed consent was obtained.

EXHALED AIR SAMPLING

Exhaled air was sampled on line and off line. Both sampling methods were performed by all subjects using three different flow rates $(50 \mathrm{ml} / \mathrm{s}, 100 \mathrm{ml} / \mathrm{s}, 150 \mathrm{ml} / \mathrm{s}$ ) in random order. All measurements were performed with the children seated and without a noseclip. Between the different manoeuvres a resting period of 2 minutes was maintained for equilibration of resting ventilatory conditions. After the exhaled air sampling procedures all subjects underwent flow-volume curve measurements using a heated Lilly-type pneumotachograph (Jaeger, Würzberg, Germany). Results of forced expiratory vital capacity (FVC) and forced expiratory volume in one second $\left(\mathrm{FEV}_{1}\right)$ are expressed as percentage of predicted values. $^{13}$

ON LINE MEASUREMENT

The measurement circuit consisted of a mouthpiece connected to a two way nonrebreathing valve (Rudolph Inc, Kansas City, MO, USA) through which the subjects inhaled ambient air when the ambient NO concentration was below $10 \mathrm{ppb}$ and NO-free medical air when the ambient NO was higher. The subjects inhaled to total lung capacity (TLC) and immediately exhaled, with a constant flow, for as long as possible into a wide bore tube with an in-line flow resistance $\left(20 \mathrm{~cm} \mathrm{H}_{2} \mathrm{O} / \mathrm{l} / \mathrm{s}\right.$; Rudolph Inc). A fine bore Teflon tube continuously sampled the exhaled air from a side-port directly after the mouthpiece at $200 \mathrm{ml} / \mathrm{min}$ for measurement of eNO. This manoeuvre was performed with three different expiratory target flows of 50,100, and $150 \mathrm{ml} / \mathrm{s}$. This produced mouth pressures of 4,7 , and $10 \mathrm{~cm}$ $\mathrm{H}_{2} \mathrm{O}$, respectively. Airflow was measured by a heated Lilly-type pneumotachograph (Jaeger, Würzberg, Germany) mounted after the resistance. A biofeedback display provided visual guidance to help the subject maintain their exhalation flow at the desired level. An end expiratory flow plateau of at least 3 seconds for the different flows was the end point of the measurement. A plateau was defined as a tracing where flow varies less than $\pm 10 \%$ around the target flow. All subjects performed this test in triplicate for each target flow. Both the NO signal and the flow signal were fed into a com- puter at a sampling rate of $20 \mathrm{~Hz}$. Values of NO and flow were obtained by calculating the mean value in defined time intervals of at least 3 seconds using custom made software. Individual mean values of eNO for each target flow were calculated from at least two acceptable manoeuvres.

OFF LINE MEASUREMENT

The collecting device consisted of a mouthpiece connected to a rigid perspex tube with a fixed flow restrictor which contained an upstream pressure transducer. ${ }^{14}$ The signal from the transducer was used to feed an LED display mounted on the tube to enable the subjects to maintain a constant flow (fig 1). Subjects were asked to take a deep breath and to perform one single exhalation with a constant flow into an NO inert and impermeable Mylar balloon (maximum capacity $1750 \mathrm{ml}$ ). Children inspired ambient air or NO-free medical air when the ambient $\mathrm{NO}$ was $10 \mathrm{ppb}$ or higher. This manoeuvre was performed with three different target flows of 50, 100 , and $150 \mathrm{ml} / \mathrm{s}$ leading to mouth pressures of 7, 20, and $35 \mathrm{~cm} \mathrm{H}_{2} \mathrm{O}$, respectively, sufficient to close the velum and prevent contamination with nasal NO. ${ }^{15} \mathrm{~A}$ sample of approximately $100 \mathrm{ml}$ was drawn from each balloon in 30 seconds by the sample tube of the NO analyser within 3 hours after collection. Values of off line measurements were calculated as the mean value during these 30 seconds of sampling. We formerly found that NO is stable for at least 6 hours in Mylar balloons. ${ }^{16}$

To investigate the influence of the exhaled dead space volume on eNO in balloons we performed additional measurements in a random subgroup of children where we adapted the off line collecting device with a low resistance, non-compliant, small NO impermeable balloon (capacity $220 \mathrm{ml}$ ) connected to the exhalation tube upstream of the fixed flow restrictor. The first $220 \mathrm{ml}$ of exhaled air was thus discarded in this small balloon, after which the large balloon was inflated with the remaining part of the exhaled volume. Short term reproducibility of the off line sampling method was assessed in a random subgroup of 15 children who repeated the manoeuvre with a flow of $100 \mathrm{ml} / \mathrm{s}$ after a 5 minute interval.

NO MEASUREMENT

NO was measured with a Sievers 280 chemiluminescence analyser (Sievers, Boulder, CO, USA) with a sensitivity of $<0.1 \mathrm{ppb}$ and a detection range of $<0.1-500000 \mathrm{ppb}$. The sample line flow was $200 \mathrm{ml} / \mathrm{min}$, the response time $200 \mathrm{~ms}$, and data were displayed with a lag time of approximately 2 seconds. The analyser was calibrated daily using certified NO gases (100 ppb and $9 \mathrm{ppm}$ ) and certified NO-free gas (HoekLoos, Barendrecht, The Netherlands).

\section{DATA ANALYSIS}

The results of eNO concentrations are expressed as geometric mean (SE). Because eNO was log-normally distributed, analyses were carried out on log transformed data by using 
Table 1 Mean (SE) characteristics of study subjects

\begin{tabular}{lll}
\hline & Healthy $(n=80)$ & "Diseased" $(n=47) *$ \\
\hline M/F & $44 / 36$ & $23 / 24$ \\
Age (months) & $166(1)$ & $170(2)$ \\
Height (cm) & $162.9(1.2)$ & $166.2(1.3)$ \\
Weight (kg) & $51.4(1.2)$ & $55.5(1.6)$ \\
FVC (\% pred) & $99(1)$ & $99(2)$ \\
FEV $_{1}$ (\% pred) & $100(1)$ & $99(2)$
\end{tabular}

$\mathrm{FVC}=$ forced vital capacity $\mathrm{FEV}_{1}=$ forced expiratory volume in one second.

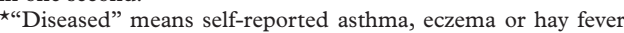
and/or recent colds.

Table 2 eNO concentrations (in ppb) of 100 children of school age measured at three different flow rates on line and off line

\begin{tabular}{lll}
\hline Flow $(\mathrm{ml} / \mathrm{s})$ & On line eNO $(p p b)$ & Off line eNO $(p p b)$ \\
\hline 50 & $15.1(1.1)$ & $18.7(1.1)$ \\
100 & $11.8(1.0)$ & $15.3(1.1)$ \\
150 & $9.6(1.1)$ & $13.7(1.1)$ \\
\hline
\end{tabular}

Values are geometric means (SE)

All differences between methods for a given flow and between flows for each method are significant $(\mathrm{p}<0.001, t$ test $)$.

the Student's $t$ test for paired or unpaired data and back transformed. Reference values of eNO for the different target flows in the healthy group are expressed as geometric mean, standard error, and $95 \%$ reference interval. The relation between age and $\mathrm{FVC}$, on the one hand, and eNO, on the other, in healthy children was assessed by Spearman's rank correlation coefficient. To analyse the withinsubject short term reproducibility the intraclass correlation coefficient $\left(r_{\mathrm{i}}\right)$ was calculated. Agreement between methods was assessed according to Bland and Altman using the ratios rather than the differences of pairs of observations as appropriate for log distributed values. A two tailed $\mathrm{p}$ value of $<0.05$ was considered significant.

\section{Results}

The characteristics of the two groups are shown in table 1. Mean values of FVC and $\mathrm{FEV}_{1}$ were normal for both groups. Both eNO sampling methods were well tolerated and performed by all children. No significant difference was observed in eNO concentrations between girls and boys. In both groups there was no significant correlation between eNO and age or lung function under all different sampling conditions. The off line sampling method was successfully performed by all subjects. With on line measurement, some children failed to blow an acceptable plateau (6-10\% of all children for various flow rates). The eNO concentrations at the on line end expiratory plateau are given in table 2 . Exhaled NO fell significantly with increasing flow under all sampling conditions in both groups (all $\mathrm{p}<0.001)$.

Table 3 Reference values of eNO (in ppb) obtained in healthy children by the different sampling methods, expressed as geometric means (SE; 95\% reference interval) in children with negative questionnaires on asthma, rhinitis, and eczema

\begin{tabular}{|c|c|c|c|c|c|c|}
\hline \multirow[b]{2}{*}{ Flow $(\mathrm{ml} / \mathrm{s})$} & \multicolumn{4}{|c|}{ Healthy children, eNO off line ( $p p b$ ) } & \multicolumn{2}{|l|}{ eNO on line (ppb) } \\
\hline & With dead space & $n$ & Without dead space & $n$ & & $n$ \\
\hline 50 & $13.5(1.0 ; 2.2$ to 29.6$)$ & 80 & $12.6(1.1 ; 4.9$ to 32.5$)$ & 29 & $10.5(1.1 ; 3.8$ to 27.8$)$ & 73 \\
\hline 100 & $11.3(1.0 ; 5.6$ to 22.4$)$ & 80 & $7.8(1.1 ; 3.2$ to 18.9$)$ & 17 & $8.2(1.0 ; 3.5$ to 19.5$)$ & 74 \\
\hline 150 & $10.4(1.0 ; 5.6$ to 19.4$)$ & 80 & - & & $6.8(1.0 ; 3.2$ to 16.3$)$ & 73 \\
\hline
\end{tabular}

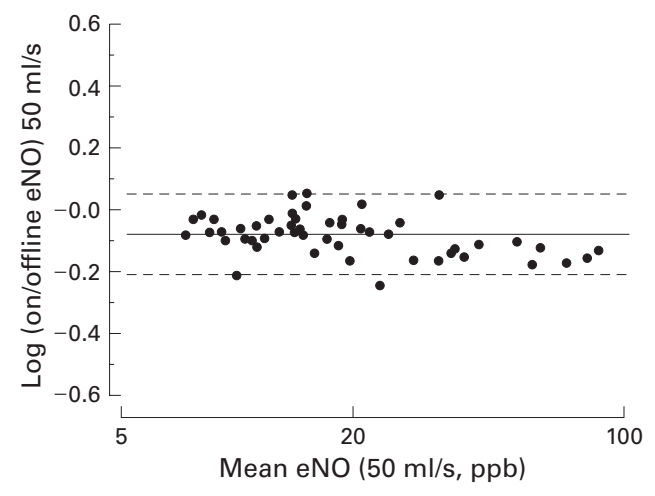

Figure 2 Modified Bland-Altman plot showing agreement of on line and off line (dead space excluded) sampling at flows of $50 \mathrm{ml} / \mathrm{s}(n=53)$. The vertical axis depicts the log ratio of on line and off line exhaled nitric oxide (eNO), the horizontal axis the geometric mean of on line and off line values on a log scale. The continuous line is the mean log ratio and the dashed lines indicate $95 \%$ agreement limits.

COMPARISON OF ON LINE AND OFF LINE METHODS One hundred children successfully performed expiratory flow rates. Their on line eNO concentration was significantly lower than their off line eNO concentration at the same target flow (table 2).

\section{INFLUENCE OF DEAD SPACE AIR ON OFF LINE} EXHALED NO

Random subgroups of children performed off line measurements with and without discarding the first $220 \mathrm{ml}$ of exhaled air with an exhalation flow rate of $50 \mathrm{ml} / \mathrm{s} \quad(n=53)$ or $100 \mathrm{ml} / \mathrm{s}(\mathrm{n}=22)$. The eNO concentrations in balloons including dead space air were significantly higher than in those without dead space air: $20.2(1.1) \mathrm{ppb} v 16.8$ (1.1) ppb for a flow rate of $50 \mathrm{ml} / \mathrm{s}$ and 15.3 (1.1) $v 10.1$ (1.2) ppb for a flow rate of $100 \mathrm{ml} / \mathrm{s}$ (both $\mathrm{p}<0.001$ ).

Analyses of agreement between $\mathrm{NO}$ values from on line and off line/dead space excluded values according to Bland and Altman, modified for $\log$ distributed data, showed a mean $\log$ ratio of $-0.08 \log (95 \%$ agreement limits -0.21 to 0.05$)$ for $50 \mathrm{ml} / \mathrm{s}$ and $-0.36(-0.66$ to -0.06 ) for $100 \mathrm{ml} / \mathrm{s}$. The ratios were largely independent of the mean values (fig 2).

REFERENCE RANGE OF EXHALED NO IN NORMAL CHILDREN OBTAINED ON LINE AND OFF LINE The eNO values obtained with the different sampling methods and target flows in the healthy group can be used as reference values. The eNO concentrations showed a log normal distribution. Geometric means and $95 \%$ reference intervals are given in table 3 . Under all the different measurement conditions the children in the "diseased" group $(n=47)$ with positive questionnaires on asthma, eczema and/or the two different sampling methods at the three 
Table 4 Differences between eNO concentrations (in ppb) of healthy $(n=73-80)$ and "diseased" ( $n=41-45)$ children measured at three different flow rates on line and off line

\begin{tabular}{ccrc}
\hline Flow rate $(\mathrm{ml} / \mathrm{s})$ & $\begin{array}{l}\text { Mean difference } \\
(p p b)\end{array}$ & $\begin{array}{l}95 \% \text { CI of } \\
\text { difference }(p p b)\end{array}$ & p value $^{*}$ \\
\hline On line & & & \\
50 & 18.9 & 13.2 to 26.1 & $<0.001$ \\
100 & 13.5 & 9.8 to 18.7 & $<0.001$ \\
150 & 11.3 & 7.8 to 14.6 & $<0.001$ \\
Off line & & & \\
50 & 19.7 & 13.8 to 26.4 & $<0.001$ \\
100 & 14.7 & 10.4 to 19.3 & $<0.001$ \\
150 & 11.8 & 8.5 to 15.6 & $<0.001$
\end{tabular}

Values are geometric means of differences and 95\% CI of differences. *Two tailed test.

rhinitis, and/or symptoms of cold during the 3 week period before the eNO measurements showed a significantly higher eNO concentration than the healthy group $(\mathrm{p}<0.001)$. Geometric mean differences between eNO concentrations of healthy and "diseased" groups of children are given in table 4 .

REPRODUCIBILITY OF OFF LINE EXHALED NO The within-method short term reproducibility of duplicate NO values obtained off line with an exhalation flow rate of $100 \mathrm{ml} / \mathrm{s}$ was excellent $\left(r_{\mathrm{i}}=0.94\right)$. The mean of all individual coefficients of variation of all eNO values was $6 \%$. Bland and Altman analysis, modified for $\log$ distributed data, showed a mean ratio for repeated eNO measurements of 1.03 (95\% agreement limits 0.87 to 1.19 ). This was independent of the mean eNO concentration within the measured range.

\section{Discussion}

This study shows that the on line eNO concentration was lower than the off line eNO concentration measured with a controlled low flow balloon sampling technique. However, when dead space air was discarded, agreement between on and off line values was good. Furthermore, we found significant differences in eNO concentrations between children with and without self-reported asthma, allergy and colds, suggesting that our off line method is sufficiently sensitive to detect minor degrees of airway inflammation in groups of otherwise healthy school age children.

The concentration of $\mathrm{NO}$ in exhaled air depends critically on the flow of exhalation, an effect that is most pronounced at low flow rates. ${ }^{11}$ It is therefore desirable to measure eNO concentrations at a constant low expiratory flow rate. Recommendations about the preferred expiratory flow rate are not in agreement. ${ }^{5910}$ A recent ATS task force recommended $50 \mathrm{ml} / \mathrm{s}$ for on line measurements for adults as well as for children. For off line measurements in adults and children a target flow of $350 \mathrm{ml} / \mathrm{s}$ is recommended. ${ }^{6}$ However, low flow rates may allow for a better detection of various disease states. ${ }^{911}$ Because of the non-uniform flow recommendations, we used three different target flows $(50,100$, and $150 \mathrm{ml} / \mathrm{s})$ to compare on line and off line sampling methods and we found a significant flow dependency of eNO in children with both methods. Off line measurement studies of eNO in children have not previously taken flow dependency into account. $^{77-19}$

We found that on line eNO values were lower than off line values under all measurement conditions. This seems to be in contrast with results from our previous study in younger children which showed similar eNO values on line and off line with a balloon sampling procedure. ${ }^{7}$ There are three possible explanations for this discrepancy. Firstly, the former study employed high flow rates of at least $250 \mathrm{ml} / \mathrm{s}$. There is much less flow dependency of eNO with high flow rates and less time for contamination. Secondly, the children in the former study were younger and had a smaller dead space volume than the school children in the present study. The influence of a smaller dead space volume will be less important in a large exhaled volume. Thirdly, the nasal contribution to the dead space air might be less important in young children. With the development and pneumatisation of the paranasal sinuses in childhood, nasal NO levels increase with age. For instance, it was recently shown in a limited number of young children that mixed oral/ nasal eNO concentrations collected off line via a face mask in a balloon were similar to eNO values obtained after tracheal intubation. ${ }^{20}$

The concentration of $\mathrm{NO}$ in the airway dead space represents a mixture of ambient NO and upper and lower airway NO which may influence eNO values with off line sampling. ${ }^{5} \mathrm{It}$ is therefore desirable to exclude dead space air with off line sampling. In adults, Paredi et $a l^{1}$ compared on line eNO concentrations obtained with off line flow- and pressurecontrolled sampling excluding dead space air and found good agreement between the techniques. The present study extends these observations and shows that exclusion of dead space volume improves the agreement of on line and off line eNO measurements in children in the recommended low flow range.

The on line eNO measurement technique proposed by the ERS ${ }^{5}$ is rather difficult for young children. ${ }^{72}$ Canady et $a l^{22}$ showed that $24 \%$ of children were unable to perform this manoeuvre. In a previous study we found that nearly $30 \%$ of children were not able to sustain a stable end expiratory flow plateau employing relatively high flows. ${ }^{7}$ In the present study only up to $10 \%$ of school children had difficulty in obtaining a stable end expiratory plateau at various flows. The expiratory flow rate of $100 \mathrm{ml} / \mathrm{s}$ with a corresponding mouth pressure of $7 \mathrm{~cm} \mathrm{H} \mathrm{H}_{2} \mathrm{O}$ had the lowest failure rate in this study. A likely explanation of the higher success rate of on line sampling in this study compared with our previous study ${ }^{7}$ is the difference in age of the study populations (median age $14.1 \mathrm{v}$ 11.7 years). In younger children in particular the on line sampling method remains difficult to perform and an alternative methodology should be developed for them.

A source of error in the present study may be nasal contamination, especially with the lowest mouth pressures - for example, $4 \mathrm{~cm} \mathrm{H}_{2} \mathrm{O}$ during on line sampling at $50 \mathrm{ml} / \mathrm{s}$. One could argue that this pressure was not high enough to 
close the soft palate, potentially leading to nasal contamination. However, a study in adults found no contamination of NO from the nasopharynx with a mouth pressure of at least $3 \mathrm{~mm} \mathrm{Hg}\left(=4 \mathrm{~cm} \mathrm{H}_{2} \mathrm{O}\right)$ using argon as a tracer gas which was applied to the nose and not retrieved in the exhaled air. ${ }^{15}$ No similar studies have been published for children. Baraldi et al observed no correlation in children between nasal and exhaled NO concentrations using a low expiratory resistance providing a mouth pressure of $3-4 \mathrm{~cm} \mathrm{H}_{2} \mathrm{O} .{ }^{19}$ Furthermore, in the present study eNO concentrations at flow rates of 100 and $150 \mathrm{ml} / \mathrm{s}$ obtained on and off line, and employing higher pressures, suggest no important contamination at lowest flows selectively. This suggests that contamination with nasal air has not introduced a bias.

Interestingly, we found significantly higher concentrations of eNO in children who reported atopic symptoms or recent colds. This suggests that eNO differentiates between healthy children and those who are likely to have minimal airway inflammation but no actual symptoms and normal lung function. We speculate that airway inflammation may already produce a significant increase in the concentration of eNO before giving rise to symptoms.

In conclusion, off line measurement of eNO is simple and feasible in school children. The off line eNO values with constant low flow, excluding dead space volume, show good agreement with on line values. Both sampling methods discriminate between groups of children with and without self-reported asthma, allergy, and colds. Off line sampling offers the possibility of studying eNO independently of the presence of an NO analyser, which could be useful for epidemiological studies and home monitoring of asthma. We propose that off line assessment of eNO should be performed using the same low flow rate of $50 \mathrm{ml} / \mathrm{s}$ as is recommended for on line assessment. ${ }^{6}$

The authors are indebted to the pupils and teachers of the "Erasmiaans Gymnasium" in Rotterdam who participated in this study.

Funding: This work was supported by research grant 94.14 from The Netherlands Asthma Foundation.
1 Lundberg JON, Weitzberg E, Lundberg JM, et al. Nitric oxide in exhaled air. Eur Respir f 1996;9:2671-80.

2 Barnes PJ, Belvisi MG. Nitric oxide and lung disease. Thorax 1993;48:1034-43.

3 Gustafsson LE, Leone AM, Persson MG, et al. Endogenous nitric oxide is present in the exhaled air of rabbits, guinea pigs and humans. Biochem Biophys Res Commun 1991;181: $852-7$.

4 Alving K, Weitzberg E, Lundberg JM. Increased amount of nitric oxide in exhaled air of asthmatics. Eur Respir f 1993; 6:1368-70.

5 Kharitonov SA, Alving K, Barnes PJ. Exhaled and nasal nitric oxide measurements: recommendations. ERS task nitric oxide measurements: recommendations

6 American Thoracic Society. Recommendations for standAmerican Thoracic Society. Recommendations for stand-
ardized procedures for the online and offline measurements of exhaled lower respiratory nitric oxide and nasal nitric oxide in adults and children. Am $\mathcal{F}$ Respir Crit Care Med 1999;160:2104-17.

7 Jöbsis Q, Schellekens SL, Kroesbergen A, et al. Sampling of exhaled nitric oxide in childeren: end-expiratory plateau, balloon and tidal breathing methods compared. Eur Respir f 1999;13:1406-10.

8 Deykin A, Halpren O, Massaro AF, et al. Expired nitric oxide after bronchoprovocation and repeated spirometry in patients with asthma. Am $\mathcal{F}$ Respir Crit Care Med 1998;157: patients

9 Silkoff PE, McClean PA, Slutsky AS, et al. Marked flow-dependence of exhaled nitric oxide using a new technique to exclude nasal nitric oxide. Am $\mathcal{F}$ Respir Crit Care Med 1997;155:260-7.

10 Högman M, Strömberg S, Schedin U, et al. Nitric oxide from the human respiratory tract efficiently quantified by standardized single breath measurements. Acta Physiol Scand 1997;159:345-6.

11 Kroesbergen A, Jöbsis Q, Bel EHD, et al. Flow-dependency of exhaled nitric oxide in children with asthma and cystic fibrosis. Eur Respir 7 1999; 14:871-5.

12 Asher MI, Keil U, Anderson HR, et al. International study of asthma and allergies in childhood (ISAAC): rationale of asthma and allergies in childhood (ISAA

13 Zapletal A, Samanek M, Paul T. Lung function in children and adolescents: methods, reference-values. Basel: Karger Verlag, 1987: 191-7.

14 Steerenberg PA, Snelder JB, Fisher PH, et al. Increased exhaled nitric oxide on days with high outdoor air pollution is of endogenous origin. Eur Respir F 1999;13:334-7.

15 Kharitonov SA, Barnes PJ. Nasal contribution to exhaled nitric oxide during exhalation against resistance or during breath holding. Thorax 1997;52:540-4.

16 Jöbsis Q, Schellekens SL, Kroesbergen A, et al. Off line sampling of exhaled air for nitric oxide measurements in children: methodological aspects. Eur Respir $f 2001$ (in press).

17 Nelson BV, Sears S, Woods J, et al. Expired nitric oxide as a marker for childhood asthma. $\mathcal{F}$ Pediatr 1997;130:423-7.

18 Artlich A, Hagenah JU, Jonas S, et al. Exhaled nitric oxide in childhood asthma. Eur F Pediatr 1996;155:698-701.

19 Baraldi E, Azzolin NM, Cracco A, et al. Reference values of exhaled nitric oxide for healthy children $6-15$ years old. Pediatr Pulmonol 1999;27:54-8.

20 Baraldi E, Dario C, Ongaro R, et al. Exhaled nitric oxide concentrations during treatment of wheezing exacerbation in infants and young children. Am $\mathcal{F}$ Respir Crit Care Med 1999;159:1284-8.

21 Paredi P, Loukides S, Ward S, et al. Exhalation flow and pressure-controlled reservoir collection of exhaled nitric oxide for remote and delayed analysis. Thorax 1998;53: $775-9$.

22 Canady RG, Platt-Mills T, Murphy A, et al. Vital capacity reservoir and online measurements of childhood nitrosopnea are linearly related: clinical implications. Am F Respir Crit Care Med 1999;159:311-4. 